\title{
Pragmatism as a Communication-Theoretical Tradition
}

An Assessment of Craig's Proposal

Mats Bergman

OpenEdition

Journals

Electronic version

URL: http://journals.openedition.org/ejpap/785

DOI: 10.4000/ejpap.785

ISSN: 2036-4091

Publisher

Associazione Pragma

Electronic reference

Mats Bergman, «Pragmatism as a Communication-Theoretical Tradition », European Journal of

Pragmatism and American Philosophy [Online], IV - 1 | 2012, Online since 23 July 2012, connection on 05 May 2019. URL : http://journals.openedition.org/ejpap/785 ; DOI : 10.4000/ejpap.785

This text was automatically generated on 5 May 2019.

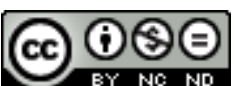

Author retains copyright and grants the European Journal of Pragmatism and American Philosophy right of first publication with the work simultaneously licensed under a Creative Commons AttributionNonCommercial-NoDerivatives 4.0 International License. 


\title{
Pragmatism as a Communication- Theoretical Tradition
}

\author{
An Assessment of Craig's Proposal
}

\author{
Mats Bergman
}

\section{AUTHOR'S NOTE}

This paper was originally presented at the Theory, Philosophy and Ethics of Communication division session at the Nordicom conference in Akureyri in August 2011. A part of the paper also formed a part of a longer paper presented at the pragmatism session at the congress of the International Communication Association in Singapore in June 2010. I wish to thank the participants in these sessions for their comments and valuable criticism. In particular, I wish to acknowledge Robert Craig's genereous reply to my paper at the ICA meeting; I may not agree with all aspects of his approach to pragmatism as a communication-theoretical tradition, but his willingness to seriously consider the advantages and disadvantages of different points of view constitutes an exemplar of pluralist pragmatism at its best.

1 Although pragmatist thought has influenced academic communication studies in a variety of ways over the last hundred years, it is only of late that distinctively pragmatist approaches to the field of communication have begun to be properly articulated. Instead of taking pragmatist philosophy as merely a secondary source of ideas and tools, several communication scholars have endorsed pragmatism as a central communicationtheoretical perspective in its own right (e.g. Craig 2007; Danisch 2007; Russill 2004, 2005, 2006, 2007, 2008; Swartz, Campbell \& Pestana 2009) - one assumed to be capable of providing a fertile general framework for inquiry into contemporary communicative practices.

2 Of such attempts to appropriate pragmatism for communication studies, Robert Craig's (2007) inclusion of a pragmatist tradition in his chart of communication theories ${ }^{1}$ constitutes one of the most prominent proposals to date. Prompted by Chris Russill's 
$(2004,2005,2006)$ reconstruction of pragmatism from a communicative point of view, Craig has revised his "metamodel" to include pragmatism as a central tradition in the field. Craig's explication is admittedly more schematic and less historically embedded than Russill's appropriation; but the former account stands out as a concise attempt to pinpoint the distinctive communication-theoretical contribution of pragmatist thought. The outcome of Craig's endeavour is a relatively definite articulation of the kernel of pragmatism from a present-day communication-theoretical point of view.

Such a demarcation faces a number of difficulties, of which the variety of different pragmatist perspectives on the market is probably the most obvious. Given the range of pragmatist thought - from the classical pragmatist ideas of Charles Peirce and William James to the neopragmatism of Richard Rorty and beyond - any significant delimitation of the pragmatist approach is likely to provoke suspicions of narrowness and undue omissions. As I will argue, Craig's revised metamodel tends to compartmentalise the tradition in a way that excludes some of its central characters. However, given Craig's systematic objectives, simply pointing out that his conception of pragmatism omits this or that figure is not compelling, as he is less concerned with the historical background than he is with moving social communication theory - including its purported pragmatist component - forward. It is therefore not sufficient to note that Craig's approach is selective and restrictive. But if it is further shown that these exclusions may be detrimental to attempts to tap the full potential of pragmatist thought, and therefore unfavourable to the fruitful development of the communication-theoretical field, the criticism becomes more potent. Consequently, I will here be less concerned with questions of historical representation or misrepresentation than with the issue of the potential implications of Craig's portrayal of pragmatism for the future development of communication inquiry.

4 This discussion is rendered particularly pertinent by the somewhat volatile state of communication studies as a social-scientific specialty. ${ }^{2}$ Sometimes viewed as merely a secondary offshoot of sociology or political science, the communication discipline - if that is an appropriate characterisation at all - is marked by self-doubt and periodic "ferments." The positive aspect of this situation is a certain receptivity to new theoretical and meta-theoretical openings; and it is as such that Craig's proposal should be viewed and possibly criticised. It is likely that the conception of pragmatism sketched in the revised metamodel will exert a noticeable influence on how the field of communication theory is presented and parsed in textbooks and anthologies of the near future. Thus, what may be at stake in this debate is how the very concept "pragmatism" is going to be understood and used in social-scientific communication studies.

5 Yet, it should be noted that Craig's primary focus is not the identification and development of a pragmatist tradition in communication theory per se, but rather the crafting of a constitutive metamodel capable of bringing some focus and genuine crossparadigm interaction to the fledgling communication-theoretical field. Indeed, in the first version of the model (Craig 1999), pragmatism does not play any explicit role at all; it is only after Russill's $(2004,2005)$ attempts to vindicate pragmatism that Craig expands the original seven-tradition matrix of first-order communication theories to include the pragmatist perspective in "Pragmatism in the Field of Communication Theory" (2007). Consequently, in order to scrutinise the particular shape Craig's conception of pragmatism takes, it is necessary to first grasp the motivations behind and the principles emerging from his ambitious metamodel project. 


\section{The Constitutive Logic of the Metamodel}

6 As the name suggests, Craig's "constitutive metamodel" strives to construct a secondorder delineation of first-order communication theories. It is driven by the belief that in spite of "the epistemological diversity and currently fragmented state of communication theory [...] the field can and should achieve a certain dialogical - dialectical coherence by adopting a common focus on communication problems in society and debating alternative practical approaches" (Craig 2007: 125). This is based on the notion that communication is a socially constructed practice, while communication theory is "a practical way of participating in a societal discourse about the norms of that practice" (Craig 2007: 127).

7 To a large extent, the metamodel - which might equally well be called a "metatheory," as Craig (2001: 232) acknowledges in his response to David Myers's criticism - can be seen as an extension of Craig's conception of the relationship between first-order theory and practice. According to this view, the development of a social practice is more or less automatically accompanied by a normative discourse, which "is characterized by specific discursive practices, or ways of using language for practical purposes" (Craig 2006: 39). Such discourse is not a neutral representation of the activity in question; it is a constitutive part of the practice, because it articulates standards, norms, techniques, etc., which render the activity culturally meaningful as well as capable of social dissemination and regulation. Consequently, in this first-order constitutive conception, every theory, "considered as an interpretation of practical knowledge, presents an idealized normative standard for practice" (Craig 2006: 44). Following James Carey (1989: 32), Craig (2007: 128) contends that every model of communication is also a model for communication. But such models or theories are themselves higher-order activities, the validity of which depends on the relevance and value of the ideal forms of practice they entail and assemble; consequently, communication theories ought to be open to second-order normative examination on such grounds.

8 Craig's metamodel is thus a theory about theories, but it is explicitly constitutive. Whereas a first-order constitutive model of communication posits that the practice under scrutiny "is the primary social process through which our meaningful common world is constructed," the metalevel constitutive viewpoint conceives of the field of deliberation and argumentation about communication theory as a debate about the practical implications of constituting communication itself in different ways (Craig 2007: 127-8). This entails the denial of an absolute reality of communication as a social practice, apart from its constitution in discourse. As Myers (2001) has noted, this is hardly a neutral standpoint, because the constitutive perspective is clearly employed in the very construction of the metatheory. One could therefore argue that such a metamodel is woefully incapable of providing a level playing field, as critics of constructionism are hardly likely to accept the constitutive supposition and join the discussion. In his reply, Craig (2001) openly acknowledges this, as well as the reflexive paradox which follows from adopting a thoroughly constitutive conception of communication theory; ${ }^{3}$ as he puts it, the constitutive metamodel is "shot through with social constructionism" (Craig 2001: 235). But in a broadly pragmatic fashion, Craig argues that a metamodel of the kind he has envisaged is simply the best alternative for advancing cross-paradigm debate available to us. It is in principle capable of detecting something of value in traditions 
opposed to its fundamental premises, for every "theory offers a particular way of constituting the process of communication from some practically oriented point of view" (Craig 2007: 128). Not even the oft-vilified linear transmission models are excluded from purview, as they may provide useful ways to talk about communicative phenomena for some particular purposes.

Consequently, the primary justification for positing a constitutive metamodel seems to be that it renders a broad field of communication theory possible, as some ground of comparison between positions that may seem to be wholly incommensurable is identified (Craig 2001: 234). That is, Craig's proposal purportedly possesses the capacity to coalesce the troublingly divergent field of first-order theories by viewing them as different ways of constructing communication for real-world ends.

The constitutive metamodel is useful because it gives the vast, otherwise disparate array of communication theories a common practical purpose to illuminate, challenge, and enrich everyday ways of talking about communication problems and practices. The constitutive metamodel constructs a coherent field by interpreting the various theories of communication as alternative ways of constituting communication in discourse for practical purposes. (Craig 2007: 129)

Furthermore, as suggested, the adoption of the constitutive metaperspective is also motivated instrumentally; supposedly, "it puts at our disposal the sum total of practical value derivable from every communication theory” (Craig 2001: 234).

Arguably, this viewpoint indicates that the constitutive metamodel is meant to be comprehensive in the sense that it can identify every communication theory worthy of the name - although, as a heuristic device, the metamodel does not claim to cover all the work done in the field (Craig 2007: 139). Furthermore, Craig's rationale for postulating the metamodel also implies that his approach can explicate the crucial distinguishing factors between such genuine first-order models of communication - elements that he articulates in a schematic matrix. Each candidate perspective is then categorised according to its unique definition of communication, its particular conceptualisation of communication problems, its characteristic "metadiscursive vocabulary" that encompasses terms for talking about communication, and the "metadiscursive commonplaces" or everyday assumptions about communication that it either affirms or challenges (Craig 2007: 129). In the second place, a bona fide member of the matrix is expected to be capable of articulating its disagreements with the other approved perspectives, thus opening up the lines of argument between different approaches to practical problems of communication.

In Craig's (1999) original presentation of the constitutive metamodel, the application of these principles for identifying communication theories results in seven basic perspectives - or, as Craig prefers to designate them, traditions - namely, the rhetorical, the semiotic, the phenomenological, the cybernetic, the sociopsychological, the sociocultural, and the critical. In addition, Craig acknowledges some secondary, hybrid forms, such as the poststructuralist viewpoint. Furthermore, he admits that this particular matrix is only one convenient way of structuring the field; it is therefore always open to corrections and additions that would require fairly substantial adjustments of the scheme.

The only restrictions on adding a tradition to the constitutive metamodel are that the proposed tradition must comprise a substantial body of thought that contributes a unique, practically consequential conceptualization of communication, significantly different from all other traditions, and that it must be 
incorporated into the matrix of the field by specifying its distinctive view of communication problems, metadiscursive vocabulary, commonplace beliefs it affirms or challenges, and topoi for argumentation vis-à-vis other traditions. Incorporating a new tradition requires that other traditions be redefined, at least to the extent that each of them has something to say (argumentative topoi) about the new tradition, and possibly in more radical ways as key ideas are reinterpreted in the new tradition. (Craig 2007: 130)

So, although the constitutive metamodel is open to changes, such modifications must be performed in an orderly fashion; the way the model is actually assembled depends on purposes at hand, but the freedom of construction is restricted by the requirement that each tradition must be articulated in relation to the other constituents of the metamodel. In other words, no matter how the matrix is actually arranged, it must explicate the relevant differences between basic first-order theories with regard to the unifying question of practical bearings. This is basically what the constitutive metamodel claims to do: to distinguish purported central traditions of communication theory in a way that articulates their differences and thereby facilitates discussion between these perspectives.

\section{Pragmatism Delineated}

If pragmatism is to be elevated to the status of a basic communication-theoretical tradition in the metamodel matrix, it must be capable of asserting its unique conception of communication in the manner outlined above. According to Craig, Russill's (2004) identification of the communication-theoretical quintessence of pragmatism succeeds in establishing the pragmatist perspective as a tradition in the sense required, although the account in question falls somewhat short of a full matrix-model articulation. Russill locates the emergence of a distinctive pragmatist approach to communication in William James's radical empiricism, which supposedly provides pragmatism with a unique perspective on communication problems; in Craig's (2007) words, "the pragmatist tradition conceptualizes communication in response to the problem of incommensurability - that is, the problem of cooperation in a pluralistic social world characterized by the absence of common, absolute standards for resolving differences" (Craig 2007: 131). This is purportedly a neglected point of view. While pragmatism has influenced communication inquiry in a myriad of different ways over the years, the specifically pragmatist conundrum of communication as the "problem of incommensurabilism in modern democratic and pluralistic societies" has not been recognised as such (Russill 2004: 32).

Next, via an interpretation of John Dewey's conception of a democratic public, the pragmatist view of communication is distinctively conceptualised in terms of triple contingency and pluralism (Craig 2007: 135).

A critical element in Dewey's theory for Russill is a triple contingency that fully situates communication in James's indeterminate, pluralistic universe. In terms of communication models, single contingency can be represented by a linear $(A \rightarrow B)$ model in which A contingently selects a message to influence $B$. Double contingency can be represented by an interactionist $(A \leftrightarrow B)$ model in which the incommensurable perspectives of $A$ and $B$ jointly determine the message (a moment of relative sameness). Triple contingency introduces a third contingent perspective that forms the context in which A and B must interact. The third perspective is represented in Dewey's theory by a pluralistic public comprising incommensurable 
group interests. The interaction of A and B is contingent on their reflexive awareness of the actions and interests of various nonpresent others who constitute the public. Inquiry (investigation of consequences) is needed to inform that reflexive social awareness. "Acting intelligently, on the basis of consequences of habitual and prospective actions, creates a standpoint of action that is neither ego's nor alter's but a third perspective" (Russill 2004: 105). Communication in society depends critically on Dewey's vision of a democratic public or pluralistic community as a context for cooperative interaction across incommensurable perspectives. (Craig 2007: 132) turn. All notions of universal norms or foundational codes of communication are purportedly abandoned, as the pragmatist affirms that "change and contingency go all the way down" (Russill 2004: 172). Communicative meaning is constantly constituted and renegotiated in three different settings of indeterminacy: individual freedom, interactive coordination, and social incommensurability - none of which can be neglected in an adequate account of communication according to this perspective. In particular, pragmatism highlights the third level of contingency, which in Piet Strydom's (2001) terms can be characterised as "the contingency that the public as the bearer of a third point of view brings into communicative relations and hence into the social process" (Strydom 2001: 165). Put differently, there are three factors that have a constitutive impact on the social situation - the individual, the dialogical pair, and the public - each of which increases the complexity and the indeterminacy of the state of affairs. In practice, this entails that social communication can be construed as a continuous attempt to manage three levels of irreducible contingency of meaning - the possible success of which is always relative, situational, and partial.

17 Consequently, Russill's account seems to fulfil the two most basic requirements of the metamodel matrix, as it provides us with a unique articulation of the problem of communication in terms of incommensurability and a distinctive conception of communication in terms of triple contingency. However, although Russill identifies an initial metadiscursive vocabulary consisting of terms such as "democracy," "publics," and "criticism" and provides some arguments for the plausibility of the pragmatist viewpoint vis-à-vis other traditions, Craig contends that this articulation of pragmatism only partly fulfils the conditions of the metamodel. Russill neglects to consider metadiscursive commonplaces, does not pursue a systematic criticism of the seven other traditions, and does not properly scrutinise how the inclusion of pragmatism in the metamodel affects the viewpoints of the other basic perspectives; but from Craig's (2007) point of view, the most serious omission is Russill's failure "to consider a full range of topoi or lines of argument against pragmatism from the traditions of communication theory, including those all-important topoi for self-criticism of pragmatism from a pragmatist point of view" (Craig 2007: 135). Hence, Craig undertakes to complete the picture.

In Craig's (2007: 136-8) version of the pragmatist tradition of communication theory, communication is conceptualised as pluralistic community and the "coordination of practical activities through discourse and reflexive inquiry," while problems of communication are extended beyond incommensurability per se to include conditions that are apt to work against pluralistic community, such as nonparticipation, dogmatism, and defective discourse practices. The revised metadiscursive vocabulary includes concepts that refer to coordinated management, such as "community," "pluralism," "interdependence," “interests," "consequences," "inquiry," "discourse," "participation,"

European Journal of Pragmatism and American Philosophy, IV - 1 | 2012 
and "cooperation." The pragmatist perspective is construed as plausible when it appeals to metadiscursive commonplaces such as "we need to cooperate despite our differences" and "the real meaning of anything is the practical difference it makes"; and it is taken to be interesting when it disputes metadiscursive commonplaces such as "there are certain truths that cannot be denied" and "there can be no cooperation with evil or falsehood."

Furthermore, Craig (2007) asserts that a common theme running through the purported pragmatist critique of the other traditions is the contention that they "attempt to restrict the triple contingency of communication, thereby limiting reflexivity through appeals to traditional beliefs (rhetoric), structured codes (semiotics), dialogical focus on the other (phenomenology), formal models (cybernetics), causal predictions (social psychology), persistent cultural patterns and social structures (sociocultural theory), and universal validity claims (Habermasian critical theory)" (Craig 2007: 138). In other words, the CraigRussill conception of pragmatist communication theory also functions as a critic of the inclination to curb indeterminacy by postulating different kinds of universal or transcendent factors. However, as Craig suggests, the most interesting aspect of this analysis may be pragmatism's self-criticism, which is divided into two predicaments. Firstly, the pragmatist is purportedly faced with the dilemma of reflexivity, which follows from the fact that pragmatism cannot be brought to fruition "without forming institutions that inevitably routinize and ritualize practices of inquiry and communication, thereby reducing contingency (the always-temporary goal of inquiry) while rendering them nonreflexive (which inhibits inquiry)" (ibid.). On the other hand, pragmatism confronts the paradox of pluralism, because it is in practice adopting a "neutral" stance in its advocacy of a pluralistic community, standing aloof from any particular interests, while at the same time theoretically denying the possibility of assuming such a neutral attitude. It is this predicament that leads to Rorty's infamous ethnocentrism; since an unbiased, universal standpoint is in principle unachievable, one might as well advocate the values and interests of one's "ethnic" community (in Rorty's case, the standards of a purported liberal America). The affirmation of "contingency all the way" comes with a price.

20 As a full-fledged tradition of communication theory in Craig's sense, pragmatism is also to be submitted to criticism from the other basic perspectives of the matrix. Frankly, these do not seem to pack much of a punch, which may be an indication of Craig's tacit pragmatist sympathies. However, from the point of view of critical theory, pragmatism can be accused of providing inadequate accounts of power and underestimating the significance of political conflict - a possible weakness that Russill $(2004,2006)$ has tried to remedy by introducing Foucauldian perspectives into the pragmatist's analytical arsenal. Furthermore, in both the cybernetic and sociocultural topoi for argumentation against pragmatism, one finds the critical contention that "pragmatism overestimates agency" (Craig 2007: 137). Although the implications of this charge are not elaborated in Craig's account, I believe it points to some characteristic difficulties for a strongly constitutive and nominalistic - conception of pragmatism.

\section{The Significance of Tradition}

21 Craig's general outline for a meta-approach to communication theory, as well as the subsequent inclusion of pragmatism in the discussion, is in many respects commendable. Rather than indifferently embracing disciplinary diversity, Craig seeks plausible grounds 
for constructive discussion in a pluralistic environment. Moreover, he does not pursue this end by indiscriminately affirming the legitimacy of every theoretical perspective under the sun, but puts forward what is clearly a normative point of view leading to categorisations of and distinctions between communication theories. Although Craig wisely leaves his metamodel open-ended and revisable, it is also exclusive, offering criteria for what may be construed as appropriate first-order communication theories. Everything does not go.

On the other hand, the benchmarks proposed by Craig provide some fairly obvious targets for criticism. Above, Myers's (2001) reproof of the constructionist slant of the original metamodel was noted. In view of the later revisions proposed by Craig, it seems reasonable to add a bias for pragmatism to this picture. In fact, Craig (2007: 133, 139-40) explicitly acknowledges that Russill is right in holding that the constitutive metamodel is in many respects a pragmatistic conception; the metamodel is a tool for tackling the problem of incommensurability - supposedly characteristic of a pragmatist construal of communication issues - in the field of communication theory. Furthermore, the metamodel adopts a pragmatist stance as it construes theories in terms of their practical orientations and as it replaces truth with utility as the fundamental evaluative criterion. Although Craig's project purportedly employs facets of all of its traditions, pragmatism belongs to the "favoured traditions" that posit a first-order constitutive model of communication. However, his proposal is also haunted by the paradox of pluralism: although there can be no neutral metamodel, the model in question professes to give a fair hearing to all of the main traditions. To Craig's (2007) credit, he openly admits that the constitutive metamodel is "a largely pragmatist project rather closely aligned with a first-order pragmatist theory of communication, although it also includes and welcomes dialogue with other incommensurable approaches" (Craig 2007: 141). But it might still be too much to ask of other traditions that they should embrace a debate so heavily loaded in favour of a constitutive pragmatist perspective, which, as we shall shortly see, is in itself a contestable interpretation.

Arguably, the attempt to find a balance between a first-order pragmatist theory of communication and a comprehensive metamodel informed by pragmatism is difficult to maintain. The first- and second-order pragmatisms qualify each other in ways that tend to render both less potent and - perhaps ironically - also less practicable. It is at any rate difficult to see how both can be consistently maintained; according to second-order principles, a first-order pragmatist should be prepared to accept that his or her favoured theory may in certain practical circumstances be inferior to its main rivals, whereas the second-order pragmatist should concede that his or her purportedly inclusive perspective is in fact determined by a restricted first-order commitment. In other words, the full-scale pragmatist must entertain something like a split personality, simultaneously affirming certain theoretical beliefs while at the same time conceding that the beliefs in question are replaceable tools. The first-level commitment - of whatever stripe it may be - is weakened by the broad instrumentalism of the meta-view.

Such arguments cast doubt on the overall feasibility of Craig's metamodel project. The status of second-order pragmatism as a sufficiently comprehensive vantage point is rendered dubious if it is understood as a product or upshot of a first-order construction. More generally, one might also question whether practical benefit or purpose constitutes a sufficiently comprehensive and neutral reference point for the task at hand. In a broadly Deweyan fashion, Craig does away with the theory/practice dualism. In this 
process, communication theories tend to become mere tools in the service of a somewhat nebulous sphere of social practice; but in order to pack any punch, this account must assume that "practical aims" are commensurable enough to provide a common ground for productive dialogue. A critic could plausibly inject that "practice" is in fact highly abstract and heavily theory-laden conception. In fact, as a constructionist, Craig ought to agree. But this threatens the metamodel with a potentially debilitating circularity, and the appeal to pragmatism does not provide any respite from this difficulty.

The problem of the status of pragmatism in Craig's metamodel can also be approached from a different angle. Namely, rather than describing and elucidating anything recognisable as a full pragmatist tradition, his proposal amounts to a particular rendering of the communicative gist of pragmatism. Admittedly, the notion of pragmatism as one tradition is highly contestable, as is the meaning and upshot of the concept of "tradition," leaving plenty of room of varying interpretations. Yet, I believe it is fair to say that such references to a tradition are typically understood as entailing a (possibly plural) history and (possibly conflicting) personalities. In this light, Craig's conception of a "tradition" turns out to be a rather peculiar one. While Russill strives to establish the historical roots of the pragmatist conception of communication - as one might expect of a reconstruction of a tradition - Craig's constitutive metamodel tends to be synchronic rather than diachronic. Not only is the presentation of the traditions included in the metamodel markedly ahistorical; it is also difficult to shake the suspicion that the metatheoretical matrix is a something of a procrustean bed for communication theories. True, the metamodel is construed as a tool for limited purposes, which does not even attempt to capture all the relevant work in the field; but it nonetheless postulates rather strict criteria for traditionhood. Thus, the question of whether the proposed demarcation of the quintessence of pragmatist communication theory constitutes a tradition in any pertinent sense at all ought to be raised. In other words, in order to legitimise the talk of a "tradition" we should be able to identify a substantial number of actual pragmatist communication theorists; one or two self-professed pragmatists does not a tradition make.

Craig provides a partial and somewhat unsatisfying answer to such worries. Based on the criteria he has established, he argues for the inclusion of communication scholars James Carey and Stanley Deetz in the broader circle of pragmatism, while "coordinated management of meaning" is singled out as a particularly pure representative of the breed (Craig 2007: 134). Thus, there would seem to be at least some bona fide pragmatists out there in the field. Yet, it feels a bit farfetched to speak of a "tradition" in this case, especially as "pragmatist" may not be part of the identified scholars' primary selfidentities. What seems to be on offer is more like a normatively constitutive paradigm. That is, it is less a matter of an actual historical practice and more of a postulation of a demarcating standard.

However, putting aside these misgivings regarding the terminological fitness of "tradition" in this context, one might argue that such concerns are ultimately trivial and beside the point, as we are not primarily concerned with intellectual history, but rather with the advancement of communication theory. In response, I would contend that the particular delineation of pragmatism proposed by Craig, if taken seriously as an intellectual guiding light, may have the adverse effect of denying communication theory the full access to pragmatism as a living philosophical and social-scientific tradition of thought. Although ostensibly rooted in the work of James and Dewey (as construed by 
Russill), Craig's conception of pragmatism does not call for a fuller engagement with their thought, and in effect discounts parallel or alternative strands emerging from other pragmatist thinkers. Ironically, in spite of its professed pluralism, the metamodel conception of pragmatism can be reductive, in effect excluding several vital facets of the broader pragmatist tradition - including its sometimes penetrating intra-tradition disputes.

This is an intricate proposition - one which I cannot fully develop in this brief review. However, for our purposes, it is sufficient to identify at least some potentially valuable ingredients of pragmatism that could contribute to the development of the communication-theoretical project, but which may be barred by Craig's conception. In conclusion, I will therefore identify three such aspects that I believe to be either obscured or excluded by the metamodel demarcation.

One key discussion within pragmatism that ought to be of significance to communication theory - and communication studies more broadly - concerns the nature of inquiry in general and scientific inquiry in particular. Significantly, the original notion of pragmatism emerges precisely from C. S. Peirce's (1877) radical conception of inquiry as a natural striving to resolve such doubts that emerge in everyday life and to replace them with optimally functional belief-habits, in addition to his characterisation of the principal hypothesis of the generic scientific method of settling doubts in terms of realism - the latter entailing that scientific inquiry implicates the hope that any particular question we may pursuing would receive a definite answer, were the investigation carried out to fruition. That is, the Peircean model of inquiry is on the one hand articulated in terms of a tendency to respond to naturally and socially compelled doubts, which are interpreted as dysfunctions or inadequacies in the habits of action that underlie our belief-systems, so that "the sole object of inquiry is the settlement of opinion" (CP 5.375); but on the other hand, this belief-doubt-inquiry-belief cycle tends to evolve into science understood broadly as a social quest for truth (pragmatically equivalent to a belief-habit that would stand, no matter what).

This belief-doubt model is reinterpreted by Dewey (LW 12) in terms of a process by which indeterminate situations are identified as problematic and eventually rendered determinate. However, in contrast to Peirce, who stresses the pursuit of truth, Dewey emphasises the transformative aspect of inquiry; it is not primarily a matter of adjusting individual and subjective habits to accord with reality, but rather a holistic and dynamic process by which entire situations (or contexts) are transformed. Successful inquiry does not entail individual satisfaction; it implies objective changes. But for Dewey, methodical inquiry is not ultimately undertaken to obtain objective knowledge, but to re-organize and improve human life. In other words, Dewey's project is unambiguously melioristic.

Given these divergent emphases, it is not surprising that Peirce's and Dewey's conceptions of inquiry and science are sometimes explicitly pitted against each other (e.g., Sleeper 1986; Talisse 2002). However, this should not lead us to overlook the substantial similarities between these pragmatist outlooks; at heart, the Peircean and Deweyan perspectives agree in replacing the ancient philosophical concern with knowledge with a dynamic conception of inquiry. Their emphasis on scientific method differs markedly from the kind of "conversationalism" associated with Rorty (and accepted by Carey). Rortyan neopragmatists tend to treat the focus on inquiry as a suspect remnant of scientism, without due consideration for the deep epistemological significance of the concept for the classical pragmatists. And although I cannot develop 
this argument at all here, there are certain reasons to maintain that the apparent divergence between Peirce and Dewey is not as wide as it may at first seem. Both of their perspectives can in the end be interpreted as laboratory approaches focused on the development of individual and social habits of action. The most pregnant point of contention may be Dewey's insistence that philosophy ought to turn its attention to the concrete problems of this world with the explicit intention of remedying particular social problems; Peirce argues for the need to protect the autonomy of science (including philosophy) from utilitarian demands, and would be quite critical of a rationalistic proposal to treat human society as a social-scientific workshop.

32 I believe that such on-going intra-tradition discussions can be of great value for the communication disciplines, given their inclination toward self-probing. The articulation of the similarities and differences between Peirce's and Dewey's respective views - and the divergence of both from the neopragmatist stance - may cast new light on the tricky question of what kinds of inquiry communication studies and communication theory actually are or can be. Perhaps going against the grain, I predict that the upshot of the inquiry into pragmatistic inquiry may provide us with reasons to curb the tendency toward constructivist/constructionist standpoints, enhancing not only our melioristic sensibilities, but also deepening our understanding of the limits of transformation and the significance of social habits (surely the main ingredients of a tradition, be it good or bad).

These considerations carry us to another, perhaps more clearly problematic aspect of Craig's demarcation of pragmatism. As noted, Craig tends to assume that pragmatism is straightforwardly well-matched with what he calls "the constitutive point of view" or simply "constructionism," in effect leaning toward an instrumentalist rejection of realism. But while it is true that pragmatism is often associated with various strands of construct-thought, and that the term "instrumentalism" can be traced to Dewey, this focus on the transformative side of things conceals the extent to which core pragmatists Peirce and Dewey, in particular - conceive of themselves as realists in contrast to nominalists and relativists. In fact, after notoriously attempting to distinguish his "pragmaticism" from other brands of pragmatism, ${ }^{4}$ Peirce quite perceptively lists a series of core "truths" purportedly accepted by all pragmatists in the broader sense of the word. Notably, these include the "acknowledgment that there are, in a Pragmatistical sense, Real habits (which Really would produce effects, under circumstances that may not happen to get actualized, and are thus Real generals)" and the "insistence upon interpreting all hypostatic abstractions in terms of what they would or might (not actually will) come to in the concrete" (CP 6.485). This habit-realism (or "scholastic" realism liberally interpreted), and its accompanying conception of the pragmatistic import of abstractions, is what the realism of pragmatism most generally amounts to. In Dewey's reading, such a realist stance is not only compatible with a moderate transformative perspective, but its very basis (LW 11: $108 \mathrm{n}$. 4).

I do not think Craig necessarily needs to reject a realism of this kind, as it is in fact largely in tune with his conception of the normative implication of practices; but in conjunction with the constitutive perspective, his nominal demarcation tends to pit pragmatism against realism in a way that muddles matters and produces pseudo-problems for the hypothetical communication-theoretical pragmatist. Recall how Craig characterises the "dilemma of reflexivity" plaguing pragmatist inquiry: it leads to habits (routines, rituals, etc.) of inquiry and communication that reduce contingency but render them 
nonreflexive (thereby inhibiting inquiry). From a Peircean-Deweyan point of view, this entails an undeservedly negative assessment of habit. Without real habits - that is, habits of action that truly work, as many of our ways of doing things seem to do - inquiry is not even possible. Instead of treating habitualisation as an obstacle to inquiry, it is more appropriate to view optimally functional habits as enablers of inquiry. Or, to put the matter differently, the pragmatist affirms the real (pragmatic) efficacy of habits (including theoretical concepts) - their consequentiality - and is therefore normatively faced with the constant challenge of producing the habits most conducive to inquiry and amelioration. In a sense, this broad kind of realism can embrace a moderate "constructionism," as inquiry entails the transformation of (real) habits; but it does not imply that belief-habits would be nothing but constructions of discourse or inquiry.

My final - and perhaps most pregnant - critical observation is that Craig's metamodel tends to disconnect pragmatism from other "traditions" in a way that may not be conducive to the stated objectives of his project. No doubt, the same point could be made with reference to many of the principal approaches he identifies, but the adverse consequences of the severance may be most tangible in the case of semiotics and pragmatism. Namely, as Craig identifies distinctive semiotic and pragmatist traditions, he in effect obscures the fact that these approaches have common roots in Peirce's rejection of Cartesianism. More than that, from a Peircean point of view, pragmatism cannot be straightforwardly removed from its semiotic context without losing something vital. By identifying the semiotic and the pragmatistic as independent traditions in communication theory, Craig seems to leave no place for the Peircean point of view, where pragmatism is primarily a theory of the clarification of meaning, closely aligned to a permeating semiotic point of view as well as a variant of common-sensist philosophy. This impression is rendered even stronger by Craig's decisively social-theoretic starting point, which seems to exclude questions pertaining to communication (or communication-like processes and phenomena) beyond the realm of the strictly social. For a semiotician of Peirce's stripe - and not incidentally, also for pragmatists like Dewey and George H. Mead - such philosophical issues should not be excluded from the purview of communication theory on the basis of disciplinary postulation.

Craig seems to have an answer handy to the worry about separating the pragmatistic from the semiotic tradition: Peirce's position may be construed as a hybrid, including elements from both traditions. However, this will not work, as Craig defines traditions as mutually incommensurable, with only "practice" providing a common point of reference. What his account will inevitably miss and exclude is the Peircean conception of a profound interconnection between the semiotic and the pragmatistic; and thereby the metamodel arguably fails to cover the full range of communication-theoretical options in the way promised. Part of the trouble is the rather unfortunate use of "incommensurable" in this context, which tends to turn Craig's traditions into mere instruments for solving particular practical problems of social communication. While such an approach may superficially appear to be in line with Deweyan "instrumentalism," it in effect postulates that the first-order practitioner of communication studies has a more or less definite set of discrete implements at his or her disposal - a toolbox from which this or that conceptual framework or intellectual instrument may be picked as need arises. feasible. Whether due to logical or psychological constraints, human inquirers - even on a 
purported metalevel - tend to look for coherent explanations and interpretations, although perfect consistency is always beyond mortal reach. Consequently, Craig must acknowledge that he views the bigger picture - the meta-metalevel - from some perspective, be it constructionist or pragmatist. As noted, he is open about his biases; but he does not appropriately recognise that this renders his postulation of incommensurable traditions incongruous, as he does not seem to find it all that difficult to explicate them within one framework of communication. For plausibility's sake, it might have been better if Craig - in good pragmatist fashion - would have chosen to stand more solidly behind his first-order beliefs while generally acknowledging the fallibility of all such perspectives.

To a large extent, the problems identified above are attributable to an attempt to maintain a degree of impartiality on the metalevel while at the same time acknowledging that no such pluralistic neutrality is pragmatically possible (and perhaps not even desirable) in view of first-level commitments. Craig's project sets out from the premise that genuine communication-theoretical paradigms are incommensurable and then moves on to postulate theoretical demarcations of major traditions that affirm this proposition. The justification for this move is that it should on the one hand elucidate the main alternatives in the field and on the other hand promote discussion between otherwise fenced-in perspectives. In my judgment, Craig's model does make a genuine contribution to the pragmatic clarification of certain major theoretical positions, although the identification of these as "traditions" is not altogether viable. If it is further acknowledged that the purported "pragmatist tradition" of communication theory is more accurately identified as a specific variant of pragmatism, then Craig's account provides a welcome opening for scrutiny of certain potential contributions of the broader pragmatist tradition to communication theory. But I feel that there is little to be gained in defining the pragmatist tradition along the lines drafted by Craig. ${ }^{5}$

With regard to the aim of promoting discussion between communication-theoretical traditions, the proposal may serve a valuable function in instigating broader debate about the nature and scope of different theoretical perspectives, but I do not foresee a productive dialogue as envisaged by Craig. If one accepts his incommensurabilist premise, but rejects the constitutive and instrumentalistic principles underlying the metamodel on first-order grounds, then meaningful exchange and cross-paradigm fertilisation ends up being both theoretically and practically impossible. That is, a non-pragmatist reading of the model on the metalevel would produce clearly defined but ultimately isolated pockets of theory on the ground. Inquiry would be blocked. But of course the reality of the field is more complex, confusing, and fecund than this schematic model would suggest. The way forward, I believe, is not the elevation of the researcher to a constitutive-pragmatist metalevel, but rather the investigation of the ways in which pragmatist philosophy may provide better (or worse) platforms for explicating communicative phenomena and developing communicative habits than its alternatives. 


\section{BIBLIOGRAPHY}

CAREY J. W., (1989), Communication as Culture: Essays on Media and Society, Winchester, Unwin Hyman.

CRAIG R. T., (1989), “Communication as a Practical Discipline," in Dervin B., Grossberg L., O'Keefe B. J., \& E. Wartella (eds.), Rethinking Communication. Volume 1: Paradigm Issues, Newbury Park, Sage Publications.

CRAIG R. T., (1999), “Communication Theory as a Field,” Communication Theory, 9 (2), 119-61.

CRAIG R. T., (2001), “Minding My Metamodel, Mending Myers,” Communication Theory, 11 (2), $231-40$.

CRAIG R. T., (2006), "Communication as a Practice," in Shepherd G. J., St. John J. \& Striphas T. (eds.), Communication as... Perspectives on Theory, Thousand Oaks, Sage.

CRAIG R. T., (2007), "Pragmatism in the Field of Communication Theory," Communication Theory, 17 (2), 125-45.

DEWEY J., (1938), Logic: The Theory of Inquiry, The Later Works of J. Dewey, 1925-53, vol. 12 (LW 12), ed. by J. A. Boydston, Carbondale and Edwardsville, Southern Illinois University Press, 1984.

MYERs D., (2001), “A Pox on All Compromises: Reply to Craig (1999),” Communication Theory, 11 (2), 218-30.

PEIRCE C. S., (1931-1958), Collected Papers of C. S. Peirce, 8 vols., ed. by C. Hartshorne, P. Weiss (vols. 1-6) and A. Burks (vols. 7-8), Cambridge (Mass.), Harvard University Press.

RUSSILL C., (2004), Toward a Pragmatist Theory of Communication (PhD Thesis), The Pennsylvania State University.

RUSSILL C., (2005), “The Road not Taken: William James's Radical Empiricism and Communication Theory," The Communication Review 8, 277-305.

RUSSILL C., (2006), “For a Pragmatist Perspective on Publics: Advancing Carey's Cultural Studies through John Dewey... and Michel Foucault?!," in Packer J. \& Robertson C. (eds.), Thinking with James Carey: Essays on Communications, Transportation, History, New York, Peter Lang.

RUSSILl C., (2007), “Communication Problems in a Pragmatist Perspective," Communication Monographs, 74 (1), 125-30.

RUSSILl C., (2008), "Through a Public Darkly: Reconstructing Pragmatist Perspectives in Communication Theory," Communication Theory, 18 (4), 478-504.

scotT F. J. D., (1973), "Peirce and Schiller and Their Correspondence," Journal of the History of Philosophy, 11 (3), 363-86

SLEEPER R. W., (1986), The Necessity of Pragmatism: John Dewey's Conception of Philosophy, New Haven, Yale University Press.

STRYDom P., (2001), “The Problem of Triple Contingency in Habermas," Sociological Theory, 19 (2), $165-86$. 
SWARTZ O., CAMPBEll K. \& C. PESTANA, (2009), Neo-pragmatism, Communication, and the Culture of

Creative Democracy, New York, Peter Lang.

TALISSE R. B., (2002), “Two Concepts of Inquiry,” Philosophical Writings 20, 69-81.

\section{NOTES}

1. Here, "communication theory" is used as an abbreviation for "social communication theory," and is furthermore restricted to approximately the sense in which Craig employs the term. The broader issue of the proper nature and limits of communication theory is beyond the scope of this brief review.

2. This disciplinary association is not self-evident; communication studies tend to spill over into different areas of the humanities as well as into technology studies and the like. But as an academic subject, communication inquiry is usually classified as a social science.

3. In Craig's (2007) words, the paradox entails that the constitutive metamodel "cannot a priori reject first-order models of communication that contradict its own assumptions without thereby contradicting those very assumptions" (Craig 2007: 128).

4. Peirce's "pragmaticism" is frequently misinterpreted as a full-scale rejection of the pragmatisms of James and F. C. S. Schiller by both Peirceans and anti-Peircean pragmatists. In fact, Peirce original introduction of the "ugly" concept clearly indicated that the "lawless rovers" that caused him concern were not his fellow-pragmatists, but certain unnamed writers in literary journals who misused the concept of "pragmatism." Yet, it is true that Peirce was critical of nominalistic and anti-logical tendencies in James and Schiller; at least once (MS 289: 11, c.1905), he referred to such thinkers as "neopragmatists" - perhaps the first use of that particular term.

5. In spite of the Peircean slant of my criticism, I remain skeptical of strict delimitations of pragmatism as a movement. Peirce himself was somewhat ambivalent regarding attempts to define pragmatism, in spite of his numerous attempts to characterise pragmatism as a philosophical principle. In a letter to Schiller he asserted: "I think we had better let pragmatism mean a vague tendency to look for the intellectual import of thought, not in what is in the mind at the time, but in the consequences. However, I do not wish to define it at present. I would let it grow and then say that it is what a certain group of thinkers who seem to understand one another think, and thus make it the name of a natural class in the Natural History fashion" (published in Scott 1973: 371).

\section{ABSTRACTS}

Of recent attempts to appropriate pragmatism for communication studies, Robert Craig's inclusion of a pragmatist "tradition" in his influential "metamodel" of communication theories constitutes one of the most prominent proposals to date. In this model, pragmatism is principally understood by contrast to other alternatives, such as phenomenology, semiotics, and rhetoric. As a communication-theoretical tradition in Craig's sense, the pragmatist approach is expected to provide distinctive articulations of the nature of communication and communication problems, expressed in a particular vocabulary. Useful as such a partitioning may be for analytical and dialogical purposes, the delimitation of pragmatism that emerges from Craig's efforts is in many 
respects problematic. After a summary of the background assumptions and disciplinary aims of Craig's project, this article identifies three serious weaknesses in his account: its neglect of relevant intra-tradition distinctions and debates, its straightforward association of pragmatism with a strongly constitutive approach to communication, and its tendency to disconnect pragmatism from other communication-theoretical positions in ways that are not conducive to his objectives. This discussion highlights the contrast between Craig's constructionist instrumentalism and the habit-realism of the classical pragmatisms of Peirce and Dewey.

\section{AUTHOR}

\section{MATS BERGMAN}

University of Helsinki

mats.bergman[at]helsinki.fi 